\title{
Los orígenes de la prensa en lengua extranjera en Málaga
}

\author{
Laura LÓPEZ ROMERO \\ Universidad de Málaga \\ lauralopezr@uma.es \\ Julio SERrano Porras \\ Universidad de Málaga \\ juliojserrano92@gmail.com
}

Recibido: 24 de marzo de 2015

Aceptado: 18 de febrero de 2016

\section{Resumen}

El asentamiento de residentes foráneos en España ha estimulado desde mediados del siglo XIX la creación de una prensa escrita en lengua extranjera con el fin de informar y de fortalecer una cohesión social entre las comunidades procedentes del exterior. El artículo que se presenta ha tomado como objeto de estudio Málaga, siendo ésta una de las provincias con mayor número actual de prensa en lengua extranjera en toda España. Esta investigación ha centrado su foco de interés en analizar dos de las primeras cabeceras escritas en lengua inglesa a principios del siglo XX: British Colony Gazette y la sección en inglés que La Unión Mercantil incorporó a sus páginas, Weekly English News.

Palabras clave: Prensa en lengua extranjera; residente extranjero; Málaga; La Unión Mercantil; British Colony Gazette; Weekly English News

\section{The origins of the foreign language press in Málaga}

\begin{abstract}
The settlement of foreign residents in Spain has led since the mid- nineteenth century the creation of a foreign language press in order to inform and serve as a vehicle for social cohesion in these communities. This article studies Málaga because it is one of the provinces with the highest current number of foreign language press in Spain. This research has focused on analyzing two of the first newspapers written in English at the beginning of XX century: British Colony Gazette and the English section of La Union Mercantil, Weekly English News.
\end{abstract}

Keywords: Foreign language press; foreign resident; Málaga; La Unión Mercantil; British Colony Gazette; Weekly English News

\section{Referencia normalizada}

López Romero, L. y Serrano Porras, J. (2016). Los orígenes de la prensa en lengua extranjera en Málaga. Historia y Comunicación Social. Vol 21, número 1, páginas 175-188.

Sumario: 1. Introducción. 2. Estado de la cuestión. 3. Los avances periodísticos de Málaga en pos de la promoción turística. 4. Bristish Colony Gazette (1926-1927): la gaceta malagueña al servicio de la comunidad británica en Málaga. 5. La Unión Mercantil y la sección en lengua inglesa Weekly English News (1930-1931): la iniciativa de la prensa local al servicio de los lectores extranjeros. 6. Conclusiones. 7. Referencias bibliográficas. 


\section{Introducción}

Los procesos migratorios a lo largo de la historia, promovidos bien por contiendas bélicas, ocupación militar, exilio político, o por otras razones de índole económica, social o cultural han ido gestando sociedades multiculturales que han compartido un mismo territorio. En este proceso de choque cultural, los medios de comunicación han contribuido a ofrecer una información de servicio enfocada a una comunidad de residentes que, desconociendo el idioma del país donde se han asentado, han necesitado de un intermediario para crear su propia concepción del territorio y de su lugar dentro él (García Galindo, 2009: 490). En este sentido, la prensa en lengua extranjera ha jugado un papel primordial. Este tipo de comunicación basado en la deslocalización hunde sus raíces en el siglo XIX, y a día de hoy sigue siendo un fenómeno muy extendido a nivel mundial.

En el caso de España, la aparición de las primeras cabeceras en lengua extranjera orientadas a una población residente y a viajeros foráneos surge en el siglo XIX en puntos de claro interés turístico como las Islas Baleares y las Islas Canarias. Los primeros ejemplos de este tipo de prensa son L'exotique, revista de ciencia y literatura, editada en Palma de Mallorca en 1842; el periódico The Tenerife News, editado en Tenerife en 1891 y la revista The Canary Islands Review, de 1903. (García Galindo, 1998; López Romero, 2009b).

El presente artículo tiene por objeto de estudio a Málaga, siendo esta provincia una de las más representativas y con mayor acopio de publicaciones periodísticas en lengua extranjera en toda España (López Romero, 2009a: 234). Los dos ejemplos extraídos para su análisis constituyen dignos avances de una modernización del periodismo escrito de la primera mitad del siglo XX. Por un lado, la edición de la gaceta Bristish Colony Gazette editada en 1926; y en segundo lugar, la sección semanal en lengua inglesa Weekly English News incorporada dentro del rotativo malagueño más importante del momento, La Unión Mercantil, en 1930. Si bien hay que puntualizar que la primera incursión en el periodismo en lengua extranjera en Málaga fue el semanario Los Aliados escrita en español, inglés y francés en 1915, (García Galindo, 1995: 258-259) la escasez de fondos hemerográficos sumado a su contenido propagandístico orientado hacia los intereses de los países aliados en la I Guerra Mundial han sido las causas principales para no haber sido incorporado a este trabajo.

Tres son los puntos clave que contextualizan a la ciudad de Málaga como foco emergente del fenómeno objeto de estudio en este artículo: la evolución del turismo, el desarrollo de las comunicaciones entre territorios y la llegada de nuevos empresarios extranjeros a tierras malagueñas. Estas características propias de la época configuraron un paisaje sólido y esperanzador para una nueva economía que impulsó de manera prometedora a Málaga y, en general, a España.

Aunque minoritaria y con una irrisoria incidencia en la economía regional, el turismo fue una actividad creciente en Andalucía en el primer tercio del siglo XX. Este desarrollo alzaría a la región como un destino turístico de primera fila a finales 
de siglo gracias a las particulares y atractivas condiciones climáticas y culturales de la zona (Pellejero, 2006: 7).

Con la intención de organizar de manera racional y programada la explotación de dicho sector, se creó la Sociedad Propagandística del Clima y Embellecimiento de Málaga. Su objetivo principal fue ensalzar el clima local como destino turístico y, de esta forma, sacar a la provincia de Málaga de la profunda depresión económica en la que se veía sumida por aquella época. (Arcas y García, 1980:42-50).

A pesar de la importancia vital del alzamiento de Málaga como un referente turístico, también existen otros elementos que orbitan alrededor del paisaje de estudio y que tienen un gran peso e influencia. Es el caso del segundo y tercer punto, el desarrollo de las comunicaciones entre territorios y la llegada de empresarios extranjeros. En cuanto a los medios de transporte, en la medida en que estos se vuelven abundantes, rápidos, cómodos, seguros y económicos, se facilita el movimiento de visitantes de un lugar a otro. Quizás el más importante de los transportes utilizados por los viajeros desde el siglo XIX es el transporte ferroviario. Todo esto sin olvidar el papel que interpretaron satisfactoriamente otros medios como el transporte marítimo y el joven mercado aéreo. En el caso de Málaga la vía marítima a través de Gibraltar era una de las modalidades de viaje junto a la vía aérea, en este caso con vuelos en aeroplano desde la ciudad francesa de Toulouse ${ }^{1}$.

A través del impulso e inversión en estos enlaces locales, nacionales e internacionales llegaron numerosas familias provenientes del exterior, atraídas por Málaga, para asentar sus raíces. Estas provenían de diversos lugares de la geografía española, como los Creixell, de origen catalán, y la familia Larios, de La Rioja. No obstante, no solo los españoles han descubierto el encanto de Málaga a lo largo de los siglos, pues familias como los Krauel y Grund, de Alemania; los Caffarena, de Italia; y los Bolín, de origen sueco, brillan con luz propia en la historia de la ciudad (Vázquez, 2011). Así, se cuentan por decenas los linajes que encontraron en el sur las condiciones ideales, tanto de vida como económicas, para desarrollar sus negocios. Inglaterra no fue diferente en este aspecto, ya que familias como los Crooke y Huelin hicieron lo propio al elegir Málaga como lugar de residencia y unirse a la oligarquía de la ciudad.

En este caldo de cultivo, fruto de la madurez del periodismo informativo malagueño y con el ánimo de plantear nuevos retos empresariales que escasamente se habían desarrollado años atrás en otros puntos del país, surgen en Málaga dos proyectos de reconocido interés investigar, orientados hacia la comunidad británica asentada en la ciudad: en 1926 nace el periódico British Colony Gazette; y en 1930, el rotativo malagueño La Unión Mercantil inaugura una sección semanal escrita en lengua inglesa bajo el título de Weekly English News.

En la realización de esta investigación se ha utilizado un enfoque metodológico cuantitativo para la extracción de datos descriptivos de las publicaciones La Unión Mercantil y British Colony Gazette, cuyos fondos están disponibles en el Archivo Municipal de Málaga. La muestra de la investigación está compuesta por los 22 números editados de la sección en inglés English Weekly News del rotativo La Unión 
Mercantil comprendidos entre el 5 de noviembre de 1930 al 9 de abril de 1931; y por otro lado, los 12 ejemplares de la gaceta British Colony Gazette editados entre el 29 de junio de 1926 y el 14 de junio de 1927.

\section{Estado de la cuestión}

El fenómeno de la comunicación periodística deslocalizada está ampliamente extendido en todo el mundo y aunque existen estudios que datan cabeceras desde los inicios del periodismo como actividad profesionalizada en el siglo XVII su auge se fecha principalmente en la etapa decimonónica.

Las primeras obras que tomaron como iniciativa la historiografía de este fenómeno datan del primer tercio del siglo XX. Así, Robert E. Park publicó en 1922 su obra The Immigrant Press and Its Control New York. Este autor fue uno de los miembros más importantes de la Escuela de Chicago y dedicó parte de su carrera al estudio de las relaciones interculturales y los medios de comunicación, entre otros ámbitos, así como el primero en analizar este tipo de prensa. En décadas posteriores hay constancia de numerosos estudios sobre la misma temática en Estados Unidos y Europa siendo los conceptos de "ethnic publications", "inmigrant press" y "foreign language press" los más empleados.

En España, los estudios que han focalizado su interés en esta temática se corresponden con los trabajos realizados por García Galindo $(1995,1998,1999,2004,2009)$ en los cuales se abordan los orígenes de la prensa en lengua extranjera, la contribución que estos realizaron en materia de promoción turística, así como la percepción del territorio y el fortalecimiento de la identidad de la comunidad foránea en Málaga. Destacan también las investigaciones de López Romero (2005, 2007, 2009), quien en 2005 elaboró el primer censo de publicaciones en lengua extranjera en la provincia de Málaga.

Otros focos geográficos han abordado esta temática en nuestro país. Destacan las aportaciones de Gómez-Escalonilla (2009) en materia de prensa para la comunidad latina; Dorn Padilla (2012), en el caso de la prensa y la comunidad de residentes alemanes en Canarias; y Novas (2014), cuyo reciente trabajo centra su estudio en el perfil del lector de la prensa en lengua inglesa en la Costa del Sol.

No obstante, todavía son muy escasas las investigaciones centradas en este fenómeno comunicativo y sobre todo desde un punto de vista historiográfico. Con este trabajo se pretende contribuir y alentar nuevas investigaciones que procuren ampliar el estudio histórico de los orígenes de la prensa en lengua extranjera en nuestro país. 


\section{Los avances periodísticos de Málaga en pos de la promoción turística}

El tipo de prensa que se practica en Málaga durante el primer tercio del siglo XX tiene sus bases siglos atrás, en el trabajo de sus antecesores desde el siglo XVII. La ciudad, que presentaba una sólida tradición impresora y un proceso de desarrollo económico que se remontaba desde el siglo XIX, fue testigo de una importante actividad periodística que se financió gracias al capital existente procedente de los negocios comerciales e industriales. Gracias a este impulso, la prensa malagueña pudo afrontar el cambio hacia un nuevo tipo de periodismo, más enfocado a la información (García Galindo, 1999: 65).

Aunque efímera, en este comienzo de siglo la creación de publicaciones en Málaga resultó activa y constante. Los primeros años del siglo XX se caracterizarían por dar continuación a la prensa del siglo XIX: el diario como altavoz de grupos de opinión y presión que utilizaban a los periódicos como plataformas de expresión (García Galindo, 1995:43. Una situación que, sin embargo, cambiaría con el paso del tiempo sobre todo tras la aparición del rotativo La Unión Mercantil (1886-1936) y el semanario gráfico La Unión Ilustrada (1909-1936).

Sin lugar a dudas, estas dos publicaciones consiguieron situar a Málaga como un referente en el mundo de la información y la comunicación en España, alcanzando una gran influencia durante la década de los 20 y 30 de la mano de la familia Creixell, sus propietarios. Durante años se posicionó como el periódico de la derecha, aunque la información actualizada que ofrecía y la amplia temática atraían a diversos sectores de la población (García Galindo, 1995: 63).

De esta forma, los medios crearon, concretamente en Málaga, el espacio ideal para recoger las bondades de la ciudad, los intereses extranjeros en diferentes lenguas y ensalzar el nombre de Málaga más allá de las fronteras de España. Junto a las páginas publicadas con información turística desde finales de siglo, los diarios de la época se lanzaron a un nuevo tipo de trabajo, arriesgado y ambicioso. Aunque en un principio no existían secciones definidas, la inserción de contenidos en otro idioma demostraba un especial interés hacia el lector extranjero. (García Galindo, 1998: 235).

Resulta trascendental nombrar el papel de las revistas malagueñas en este trabajo colectivo de acercamiento al viajero. Ejemplos como El Pregón, dirigido por José Blasco Alarcón, y La Unión Ilustrada, semanario gráfico de La Unión Mercantil, fomentaban y difundían a través de la palabra y la imagen en español los múltiples valores de la ciudad de Málaga. Cabe destacar, de igual manera, la labor de la revista anual religiosa La Saeta. Editada por Francisco Morales López, nació en 1922 con el fin engrandecer la Semana Santa malagueña, tanto a nivel local como nacional. Sin embargo, a partir de 1931, amplió este objetivo con vistas internacionales al añadir el programa de las fiestas íntegramente en lengua inglesa, apoyada en su parte inferior con una publicidad, también en idioma extranjero.

De igual manera, existió respuesta por parte de la administración pública con la publicación Turismo en Málaga, preocupada por incentivar el turismo ante las nece- 
sidades económicas y frente a un nuevo público necesitado de información. Estas mismas características formaron el caldo de cultivo perfecto para la creación de las publicaciones anteriores y, además, de trabajos en lengua foránea como Los Aliados, British Colony Gazette y la edición de la sección Weekly English News, de La Unión Mercantil (García Galindo, 2004: 175).

Así, la explotación y embellecimiento del clima de la Costa del Sol embanderó el ataque colectivo de escritores, periodistas y profesionales malagueños, el cual no solo abrazó a la Málaga veraniega, sino sobre todo promocionó la temporada invernal de la ciudad, decididos a convertir a Málaga en un destino de referencia tanto para los viajeros fugaces como para los prolongados en el tiempo.

\section{Bristish Colony Gazette (1926-1927): la gaceta malagueña al servicio de la comunidad británica en Málaga}

El estudio de la prensa en lengua extranjera en Málaga no se inicia con la publicación que tiene por objeto de estudio este epígrafe. No obstante, es conveniente catalogar la existencia de dos periódicos que anteceden a la British Colony Gazette, de 1926.

El primer indicio que se conoce corresponde al rotativo denominado The Peninsular Post and North African Garelle, de 1914, el cual incorporaba un suplemento en español, del que no se tiene constancia física en los archivos salvo por la mención que se recoge en los apuntes de la obra de Narciso Díaz de Escovar (García Galindo, 1994:263).

En 1915 ve la luz el semanario Los Aliados, escrito en español, inglés y francés, con la misión de informar y convencer al público imparcial sobre la barbarie germana, defendiendo los intereses aliados en España. Existe constancia de su edición en octubre de 1915 pero se desconoce su trayectoria posterior dada la falta de fondos catalogados (García Galindo, 1999:40).

No sería hasta 1926 cuando un nuevo proyecto periodístico apostara por ofrecer a la comunidad de residentes británicos un soporte informativo en su lengua materna, naciendo así el 29 de junio de aquel año el periódico mensual British Colony Gazette bajo la dirección de Agustín Pérez Martín, director a su vez de la Spanish Traveller Information, y la edición a cargo de Ernesto Yaldwyn, quien ejercía al mismo tiempo de corresponsal en Málaga para el rotativo The Times. Ambas personalidades formaban parte del Círculo Inglés de Málaga.

British Colony Gazette estaba escrito también en español. Según informa el propio periódico, por mandato legal se obligaba a que todo artículo publicado en idioma extranjero debía ser traducido también al español. Desconocemos por tanto si la verdadera intención de la gaceta era publicar en los dos idiomas para dirigirse tanto a la población local como a la extranjera, o si bien fue una imposición. 
A lo largo de sus doce números publicados entre junio de 1926 y junio de 1927, el periódico inicia su impresión con ocho páginas, alcanzando doce en sus últimos números. Sin datos de dirección, edición, impresión ni siquiera precio de ejemplar o suscripción, se deduce que la gaceta fue un producto informativo editado con el esfuerzo económico de aquellas personas que apostaron por este proyecto, y que era distribuida como bien indica el periódico en sus páginas interiores a destinatarios fijos como:

"hoteles, cafés, barcos, bureaux de turismo particulares, autoridades industriales y comerciantes (...) no solamente en España y la Gran Bretaña, sino también en las colonias inglesas, y los dominios, a la par que Estados Unidos y Suramérica (...) y el Bureau Español de Turismo en Londres". ${ }^{2}$

Su financiación procedía tanto de donaciones personales, apoyo institucional del gobierno local, así como de la publicidad inserta en sus páginas, ubicada principalmente en portada y en las dos últimas hojas y con la preferencia temática de empresas relacionadas con entidades aseguradoras, alquiler de automóviles, trayectos en barco y en alguna ocasión empresas locales relacionadas con el embalaje, imprentas, etc.

Los difíciles inicios de la empresa periodística fueron descritos por la inquisitiva y procaz pluma del redactor que firmaba bajo el pseudónimo Globin:

"Todos somos testigos del nacimiento a manera de setas de la Gaceta de la Colonia Británica, obra debido únicamente a la iniciativa, generosidad, energía y patriotismo de un solo hombre: el editor actual (...) pese a los muchos obstáculos y desalientos que para ellos se interpusieron. (...) A excepción de uno o dos casos dignos de alabanza, todos se han cruzado de brazos, permitiendo que un solo hombre asumiera solo la pesada carga de tan loable empresa, sin tomar parte ni en los gastos ni en el trabajo. Esto señores, no está bien, no es equitativo, no es jugar limpio. (...) Ha mejorado la situación notablemente, ya que muchos socios, tanto españoles como británicos (...) han acudido como héroes en defensa del periódico"3.

British Colony Gazette nació con un doble objetivo. Por un lado, servir de propaganda turística de Málaga hacia los visitantes y residentes extranjeros, y por otro lado, como nexo de unión e identidad de la comunidad británica de la ciudad

\footnotetext{
“en pro de más estrecha unión entre los miembros de la colonia británica en Málaga, tan recientemente amenazada de quebrantamiento y cisma". ${ }^{4}$
}

En la evolución del semanario hay que destacar diferentes secciones que han copado las páginas mes a mes: personalidades prominentes, cartas al director, poesías, nuestro buzón, nuestro libro de notas, sub rosa, notas de sociedad, charla de muchas cosas, contestaciones a correspondencia, entre los libros, etc. Los debates políticos o las noticias internacionales no formaban parte de los fines de la gaceta. Da fe de ello el redactor alias Beau Lynne, quien expresó una queja en referencia a la prohibición de estos temas. ${ }^{5}$

De obligada aparición fue siempre en la primera página un reportaje turístico sobre la ciudad o los pueblos vecinos. Destacan las excursiones recomendadas a Ronda, Antequera, El Chorro, Fuengirola, Coín, así como a monumentos de la ciudad. 
Fotografía y publicidad son dos elementos que han ido creciendo a lo largo de los sucesivos números. Destaca así el ejemplar del 30 de marzo de 1927 dedicado casi en exclusiva a la Semana Santa malagueña, con elevado número de fotografías, todas ellas cedidas por la corporación municipal, quedando constancia de la estrecha colaboración de la ciudadanía local para con el rotativo.

Huelga decir que las páginas de esta publicación dibujaron un bello retrato de la vida social, cultural y económica de la comunidad británica en Málaga bajo el siempre denominador común del humor, tanto en sus textos como en el diseño de sus anuncios publicitarios. Aunque también la crítica y la sátira coparon más de un artículo de opinión.

La comunidad británica en la ciudad es dividida por la gaceta entre los viajeros y los extranjeros residentes en la ciudad: "Cuando las hojas empiezan a caer, hay muchos ingleses que a su vez empiezan a considerar donde pueden buscar el sol desde noviembre a abril." ${ }^{\prime 6}$

Es especialmente importante mencionar la existencia de la Biblioteca Inglesa, círculo de reuniones creada a iniciativa de personajes de la élite británica como Laureano Colville y el cónsul inglés Sr. Hall, entre otros. En el también llamado Círculo Inglés se celebraban reuniones para tratar temas relacionados con la vida de los residentes británicos asentados en la ciudad. También funcionaba como sala de lectura donde se podían consultar ejemplares de los principales periódicos ingleses, libros, novelas biografías, etc. La familia Larios ofreció en alquiler un edificio donde agrupar tanto el consulado como la biblioteca inglesa. Como socia honorífica destacó la princesa Beatriz de Battenberg, hija de la reina Victoria de Inglaterra y hermana de la reina española Victoria Eugenia de Battenberg. La aristócrata recibía British Colony Gazette todos los meses, para orgullo y honor de sus trabajadores.

A través de la lectura de la gaceta se da a conocer la existencia de otro periódico en Málaga escrito en español y en inglés, disponible en la Biblioteca Inglesa, calificada como "empresa particular y no de la Biblioteca" . Se desconoce su existencia, pudiéndose tratar de una hoja volante.

El fin de la gaceta es incierto por cuanto no se anuncia con claridad. El último número disponible en los archivos corresponde al editado el 14 de junio de 1927, un año después de iniciar su andadura. Si bien el periódico anuncia su intención de continuar, la lectura del primer artículo "Aquí se termina el primer año", induce a pensar que no habrá una edición futura:

"Puede ser que dure más. Esto depende en los deseos de los residentes ingleses de Málaga, y en la bondad del pueblo malagueño que tan cariñosa acogida nos sigue proporcionando. (...) Es nuestra intención ampliar, si podemos, nuestro radio de acción, buscando de las autoridades su colaboración en hacer una propaganda más intensa". 8

Posiblemente motivos económicos fueran la causa del cierre. De hecho el periódico deja entrever problemas de referida índole en la siguiente aseveración: 
“A ver si con una propaganda todavía más intensa logramos pagar una parte de la deuda".?

A pesar de ser este la última edición disponible en los archivos, hay constancia de un número posterior editado en el mes de julio de 1927 correspondiente al número 1 del volumen 2, según los apuntes de Narciso Díaz de Escovar, el cual aseguraba tener en su biblioteca privada el ejemplar antes referido. (Díaz de Escovar, 2000: 252).

\section{La Unión Mercantil y la sección en lengua inglesa Weekly English News (1930- 1931): la iniciativa de la prensa local al servicio de los lectores extranjeros}

La Unión Mercantil demostró realmente el interés por servir a toda la ciudadanía malagueña de la época cuando añadió en noviembre de 1930 una página semanal en inglés, Weekly English News. Esta decisión empresarial es digna de mención por cuanto la iniciativa no fue la creación de una sección independiente, sino inserta en el rotativo de mayor tirada del momento en la ciudad y de gran popularidad en toda Andalucía. Por sus características, razón de ser y fecha de surgimiento, García Galindo lo considera uno de los antecedentes del actual rotativo semanal Sur in English, nacido en 1984, y que actualmente sigue vigente. (García Galindo, 2004: 175).

Años antes de la publicación del suplemento, el diario, en su versión en español, informaba de forma habitual de la Sociedad Propagandística del Clima y el Embellecimiento de Málaga, así como de sus actividades. Las revistas y diarios ingleses se hacían eco de las bondades del clima y la ciudad de Málaga a través de sus compatriotas o gracias a políticos y representantes en suelo español. La intención principal del novedoso proyecto de La Unión Mercantil era introducir la Málaga y Andalucía invernal a los turistas ingleses que residían en la ciudad en dicha temporada. Con este objetivo, los diferentes artículos, cartas y consejos publicados a lo largo de los cinco meses de vida de la publicación aconsejan la visita a Málaga y, posteriormente, a Andalucía, nombrando zonas como Ronda, Córdoba, Sevilla y Comares. Además, se presta especial atención a otros temas relacionados, como son la Semana Santa, la fiesta taurina y los eventos organizados por la sociedad inglesa en suelo malagueño.

El día 6 de noviembre de 1930, La Unión Mercantil publicó el siguiente mensaje para dar la bienvenida a la sección Weekly English News, la cual vio la luz cada jueves hasta el 9 de abril de 1931.

“A partir de hoy publicará LA UNIÓN MERCANTIL semanalmente una nueva sección, en idioma inglés dedicada a la colonia británica en Málaga, a los numerosos turistas de habla inglesa que nos visitan de modo asiduo y a los invernantes del país británico, huéspedes nuestros, cada año en mayor densidad. Es una innovación que, de fijo, interesará a ese nuevo núcleo de intereses"10.

De esta manera, con un escueto mensaje en inglés y español en el centro de la portada, La Unión Mercantil procedía a inaugurar el primer suplemento totalmente 
en inglés, publicado por un diario español. Según la propia Unión Mercantil, el primer periódico de España que lleva a cabo un proyecto de estas características en idioma anglosajón. A pesar de esta innovación, el diario nombra a La Vanguardia, en Barcelona, como predecesor e inspirador en el camino, con la impresión en 1927 de una hoja escrita en inglés, francés y alemán.

Como causas que propician el lanzamiento del suplemento en inglés, La Unión Mercantil resalta la constante demanda de información veraz y actualizada "sobre todo lo que merece la pena saber para un visitante del sur de España que no habla español". Desde un primer momento, el periódico califica como difícil el hecho de transmitir información totalmente fiable y actualizada, debido especialmente a las condiciones cambiantes que acontecen en el momento. No obstante, el diario malagueño sí muestra la intención de hacer su mejor esfuerzo y estar en contacto con las mejores fuentes de información.

De esta forma, y siguiendo la estela de La Unión Mercantil como referente en Andalucía y Marruecos, el periódico propone cada jueves desde el 6 de noviembre Weekly English News como un camino para proporcionar resúmenes de las últimas noticias globales y locales, listas de visitantes, descripciones de excursiones, artículos cortos sobre Málaga y Andalucía y cualquier elemento que pueda resultar útil e interesante al viajero y residente inglés.

Los apartados de Weekly English News cubrían una gran cantidad de temáticas como las bondades turísticas de Málaga o Andalucía e incluía secciones fijas como Social Notes, Visitors, Latest World News, For sale y una viñeta final.

El apartado de noticias, situado en la zona central de la página, comprende el ámbito nacional e internacional. La intención principal, como afirma la propia Unión Mercantil en su carta de presentación del día 6 de noviembre, es introducir Málaga y Andalucía en invierno a los turistas ingleses que residen en la ciudad en dicha temporada. Como base a este fin, gran parte de los artículos publicados enumeran las características de la ciudad y Andalucía, aconsejan al viajero diferentes planes y actividades a realizar y, en general, fomentan la imagen de Málaga y otras zonas como Ronda, Córdoba y Sevilla como destino turístico singular e inigualable en el mundo.

Aunque una parte importante del contenido de la hoja de La Unión Mercantil está dirigido a fomentar la imagen de Málaga y Andalucía mediante artículos, cartas y decálogos de consejos, una característica que hace diferente a Weekly English News de otros suplementos meramente propagandísticos es la introducción de noticias totalmente en inglés y que abarcan el ámbito local, referido a Málaga; nacional, relacionado con la política, economía y sucesos de España; e internacional, tanto con información de Inglaterra como del resto de países, utilizando para ello diarios como el Daily Mail y The Times, entre otros. Constituye esta una de las principales diferencias con British Colony Gazette, cuya labor informativa era inexistente.

El origen de la información en los artículos publicados por La Unión Mercantil en su suplemento en inglés es de producción propia y también procede de diarios en 
lengua extranjera. $\mathrm{Al}$ igual que en el resto del rotativo, las noticias no se encuentran firmadas por el autor del escrito, excepto cuando el contenido corresponde a una personalidad inglesa que da su opinión sobre Málaga, Andalucía o España.

El servicio a la comunidad británica es una labor que ejerció La Unión Mercantil al facilitar la dirección y un número de teléfono para fomentar la interacción con sus lectores, los cuales encontraban en Weekly English News un altavoz donde transmitir sus experiencias en suelo español. Este periodismo de servicio ha continuado en su homólogo, Sur in English, 53 años después, y en gran parte de la actual prensa en lengua extranjera en España. (López Romero, 2005).

Por último, resulta destacable que ni en los contenidos locales, nacionales ni internacional de Weekly English News se produce una traducción íntegra desde los textos en español de La Unión Mercantil. En todos los casos, la información resulta originalmente escrita por los periodistas del suplemento, lo cual se debe a que, bajo la intención de comunicarse de manera clara y directa con los lectores de habla inglesa, resulta imposible traducir de manera literal los contenidos de La Unión Mercantil en español, ya que las noticias para el público inglés exigen otro tono y nivel de explicación.

En los cinco meses de vida de Weekly English News las personalidades que aparecen con mayor asiduidad están relacionadas con la política, la realeza y las instituciones de la colonia británica en Málaga. Por otro lado, partidos políticos y clubs también presentan un espacio destacado en el suplemento.

La realeza, tanto española como inglesa, también ocupa un lugar destacado en las informaciones. La princesa Beatriz también está presente en las páginas del rotativo, así como las personalidades y partidos políticos de Inglaterra. En cuanto a las informaciones de las colonias, la figura de Mahatma Gandhi aparece en varias ocasiones. Además, cabe destacar que los hoteles de Málaga y las figuras ingleses hospedadas se repiten a lo largo de los días, pero este contenido pertenece a la sección Social Notes.

Al suplemento Weekly English News no le faltó apoyo publicitario desde el primer día. En torno a una veintena de empresas y particulares se anunciaban cada jueves. El 6 de abril, primera fecha de impresión, ya poseía un apartado dedicado a cinco columnas con publicidad diseñada y amoldada para el público inglés. Destacan los anuncios de compañías internacionales de viaje marítimo como German East African Lines, empresas hoteleras y pensiones como la Hacienda de Giro o el Hotel Reina Victoria, venta de terrenos y propiedades y zonas para de restauración y entretenimiento como los Baños del Carmen y el Cine Goya. También anuncios de farmacias, hostales, zapaterías, clínicas dentales y médicas y restaurantes. Sin embargo, la localización de estas compañías señala directamente a lo local, exceptuando tres casos puntuales, a nivel andaluz e internacional: Hotel Majestic, en Sevilla, y German East African Lines, en Alemania, y Wagon Lits Cook, en Bélgica, respectivamente. Reseñable el hecho de que no había empresas a nivel nacional y que no solo se anunciaban compañías, ya que había casos como los de malagueños o españoles de otras zonas que ofertaban clases de castellano o lecciones de guitarra a extranjeros. 
Sin lugar a dudas, la publicación cada jueves de Weekly English News supuso un avance de gran importancia en la creación histórica de una prensa local dirigida a los viajeros y turistas. La difusión internacional del destino y el entendimiento con los viajantes se antoja vital para lograr un espacio de referencia para la llegada de turistas. En este sentido, se entiende que el suplemento de La Unión Mercantil cumplió con estos puntos necesarios y satisfizo tanto las necesidades de Málaga como la de los viajeros de la época.

Por otro lado, Weekly English News se mantuvo en la quinta página de cada número de La Unión Mercantil hasta el 9 de abril de 1931, es decir, la totalidad de la etapa invernal turística. Si la publicación no hubiese conseguido el éxito esperado o la respuesta adecuada de la comunidad inglesa, La Unión Mercantil habría desistido y el proyecto no habría cumplido la fecha que conocemos.

El final de Weekly English News sucedió el 9 de abril de 1931. Las razones de su cierre se encuentran en el final de la época invernal en Málaga, ya que La Unión Mercantil ya informó en el primer número del suplemento que el período de publicación comprendería los meses precedentes a la época estival.

No obstante, aunque la propia Unión Mercantil señaló en el mensaje de despedida del 9 de abril que Weekly English News volvería al diario en otoño, entorno al 1 de noviembre de 1931, la hoja jamás volvió a ser reproducida.

No se especifican las razones del fin de la publicación, pero existen ciertas circunstancias especiales que invitan a deducir las verdaderas causas. Una de ellas y, posiblemente, la más importante es el asalto a la sede de La Unión Mercantil el mismo día de proclamación de la II República en España. Este suceso, que provocó la ausencia del diario en las calles de Málaga durante varias fechas, no fue el último acto de violencia contra el periódico. La ideología conservadora y favorable a la monarquía convirtió a La Unión Mercantil en objeto de odio habitual hasta su cierre en 1936 más los posteriores asesinatos de Antonio Creixell de Pablo-Blanco y sus tres hijos con residencia en Madrid, y en Málaga el directivo Ángel Creixell de Pablo-Blanco y Antonio Baena Gómez, presidente del consejo de administración. (Vázquez, 2011: 44).

\section{Conclusiones}

La coyuntura actual que vislumbra un panorama mediático orientado a la comunidad extranjera en la Costa del Sol, y en general, en toda España, ha de entenderse como un fenómeno diacrónico que hunde sus raíces a principios del siglo XX, en el caso de Málaga, y a medios del XIX si nos referimos a otros puntos como Islas Baleares e Islas Canarias.

El caso malagueño es uno de los más importantes en todo el país no sólo por la relevancia de estas primeras publicaciones que han sido trabajadas en este artículo 
sino por la trayectoria tan prolífica que ha experimentado este tipo de periodismo deslocalizado hasta nuestro días.

La contribución que hicieron British Colony Gazette así como La Unión Mercantil a través de su suplemento en inglés, viene a asentar una realidad sociocultural de gran relevancia en la ubicación geográfica en la que se encuentra la Costa del Sol, y por añadidura todo el litoral sur de la península ibérica.

La interconexión de sociedades multiculturales como fruto del desarrollo económico, político o social ha dado como fruto una necesidad básica informativa que la prensa escrita ha ido cubriendo con creces.

Para la comunidad británica en Málaga, la obligatoriedad de contribuir a sus necesidades y de fortalecer una identidad sólida y cohesionada en un país diferente al de nacimiento ha permitido a la prensa cumplir una función de servicio de gran valor social y cultural.

La iniciativa periodística que enarboló en primer lugar Los Aliados como continuación de The Peninsular Post y más tarde Bristish Colony Gazette fue mejorada por el suplemento inglés que La Unión Mercantil elaboró años después en 1930. Estos antecedentes suponen una riqueza histórica, periodística y cultural de gran valor que ha servido para que este fenómeno de comunicación se desarrolle con mayor ritmo a partir de la etapa del denominado boom turístico en los años 60 y del turismo residencial cuyos inicios se ubican en la década de los 70 . Fruto de este contexto económico y turístico nacen revistas de gran importancia a nivel nacional como Lookout (19632004), el rotativo Sur in English creado en 1984 y un centenar más de publicaciones periodistas que han ido surgiendo a demanda de las comunidades extranjeras hasta el día de hoy.

\section{Referencias bibliográficas}

ARCAS, F. y GARCÍA, A. (1980). "Los orígenes del turismo malagueño. La Sociedad Propagandística del Clima y Embellecimiento de Málaga”. En: Jábega, n³2. p.42-50.

DÍAZ DE ESCOVAR, N. (2000). Bibliografia de la prensa malagueña: Apuntes de la historia del periodismo en la provincia de Málaga. Málaga: El Corte Inglés.

DORN PADILLA (2012). "Prensa y turismo alemán en Canarias". En: Actas del IV Congreso Internacional Latina de Comunicación Social, Universidad de La Laguna, Tenerife, pp. 1-20.

GARCÍA GALINDO, J.A. (2009). "La imagen de España en los medios de los residentes extranjeros". En: BERGASA, V., et al., (ed.) (2009). ¿Verdades cansadas? Imágenes y estereotipos acerca del mundo hispánico en Europa. Madrid: Consejo Superior de Investigaciones Científicas. pp. 489-501.

(2004). "Prensa y turismo en España (Málaga, 1872-1936)". En: LUDEC, N. y DUBOSQUET, F. (coord.) (2004). Centros y periferias: prensa, impresos y terri- 
torios en el mundo hispánico contemporáneo: homenaje a Jacqueline Covo-Maurice. España: PILAR. pp. 169-178.

(1999). La prensa malagueña : (1900-1931): estudio analítico y descriptivo. Málaga : Ayuntamiento, Ảrea de Cultura.

(1998). "El papel de los medios de comunicación en la configuración y promoción de la Costa del Sol". En: MELLADO, V. y GRANADOS, V. (coords.) (1998) Historia de la Costa del Sol. Málaga: Diario Sur. pp. 233-240.

(1995) J.A., Prensa y Sociedad en Málaga, 1875-1923. Málaga: Edinford.

GÓMEZ ESCALONILLA, G. (coord.) (2008). Voces de la inmigración, medios latinos en Madrid. Madrid: Editorial Universitas.

LÓPEZ ROMERO, L. (2009). "Prensa extranjera en España. La integración social a través de los medios escritos". En: Telos. Cuadernos de Comunicación e Innovación, $\mathrm{n}^{\circ} 80$, pp. 116-124.

(2009). Prensa y comunidad extranjera en España. Estudio descriptivo y analítico de Málaga. Madrid: Quiasmo editorial.

(2005). Estructura de la prensa escrita en lengua extranjera en la provincia de Málaga. Periodismo de servicio o periodismo de integración social. En: MAZÓN, T., y ALEDO, A., Turismo residencial y cambio social. Nuevas perspectivas teóricas y empíricas. Alicante: Editorial Aguaclara. p. 461468.

NOVAS (2014). La prensa extranjera como herramienta de integración para las comunidades foráneas. Los periódicos en lengua inglesa editados en la Costa del Sol. Proyecto Final de Máster [sin publicar]. Universidad de Málaga.

PARK, R. (1922). The inmigrant press and its control. Nueva York y Londres: Harper \& Brother.

PELLEJERO, C. (2006). Estadísticas históricas sobre el turismo en Andalucía. Siglo $X X$. Sevilla: Instituto de Estadística de Andalucía.

VÁZQUEZ, A. (2011). La Mirada de Málaga. Historia y vida de 20 familias malagueñas. Málaga: Andalucía Editorial.

\section{Notas}

1 British Colony Gazette, $n^{\circ} 5$, p.7. 21 de octubre de 1926.

2 British Colony Gazette, nº12, p.3 , 14 de junio de 1927.

3 British Colony Gazette, n³, p.5, 18 de agosto de 1916.

4 British Colony Gazette, n³, p.5, 18 de agosto de 1916.

5 "Nada en absoluto", En: British Colony Gazette, n6, p.4., 30 de noviembre de 1926.

${ }^{6}$ British Colony Gazette, n5, p.7, 21 de octubre de 1926.

7 “La Biblioteca Británica-Málaga: Una apreciación” En: British Colony Gazette, no 7, p.5, 21 de octubre de 1926.

8 British Colony Gazette, nº12, pp. 2-3, 14 de junio de 1927.

9 Idem.

10 Weekly English News, p1. 9 de abril de 1931. 